DOI: $10.17805 / z p u .2015 .2 .29$

\title{
Программа исследования типов психологического отношения к табакокурению (на примере некурящих представителей молодежи)*
}

\author{
В. П. ПОзНЯКОВ \\ (ИНСТИТУТ ПСИХОЛОГИИ РАН, МОСКОВСКИЙ ГУМАНИТАРНЫЙ УНИВЕРСИТЕТ), \\ C. A. РЕШЕTKO \\ (ИнСтИтУт пСИХОЛОГИИ РАН)
}

В статье представлена программа исследования типов психологического отношения к табакокурению (на примере некурящих представителей молодежи). Согласно современным представлениям о психологических отношениях, обсуждаемым в российской психологии (А. Л. Журавлев, В. П. Позняков), в их структуре выделяют такие компоненты, как когнитивный, эмоциональный, ценностный и поведенческий. В основе данного исследования лежит предположение, что типы психологического отношения к табакокурению будут обусловлены различной выраженностью компонентов отношения.

Целью исследования является выявление и описание типов психологического отношения некурящих представителей молодежи к табакокурению. Объектом исследования выступили некурящие представители студенческой молодежи в возрасте от 18 до 22 лет (жители г. Москвы и Московской области). Для сбора эмпирических данных использованы методики: авторская анкета «Исследование психологического отношения к табакокурению", методика "Уровень соотношения "ценности" и "доступности" в различных жизненных сферах» (Е. Б. Фанталова), цветовой тест отношений применительно к табакокурению, семантический дифференциал, 16-факторный личностный опросник Кеттелла.

Представлены результаты первых двух этапов исследования. Первый - проведение теоретического анализа психологических исследований табакокурения и понятия «отношение». Второй этап - пилотажное исследование, в результате которого были скорректированы задачи исследования и вопросы в авторской анкете. На основании полученных данных с использованием кластерного анализа были выделены четыре группы респондентов, различающихся по содержанию компонентов психологического отношения к табакокурению.

Использование дискриминантного анализа позволило выявить значимые социальнопсихологические характеристики некурящих представителей молодежи. Наибольшую значимость имеют показатели E(подчиненность - властность), G (безответственность ответственность), М (практичный - творческий) (16-факторный личностный опросник Кеттелла).

В последующем планируется проведение основного эмпирического исследования.

Ключевые слова: табакокурение, психологические отношения, молодежь, некурящие, отношение к курению.

\section{BВЕАЕНИЕ}

$\mathrm{B}$ настоящее время проблема табакокурения привлекает все больше внимания как средств массовой информации и общественных деятелей, так и представителей различных отраслей научного знания. Изначально медицинская, данная проблема в настоящее время включает междисциплинарное содержание, а ее изучение характеризуется свойствами, типичными для междисциплинарного исследования в пси-

* Статья подготовлена при финансовой поддержке РГНФ (грант № 15-06-10231а, «Социально-психологические факторы успешного отказа от курения»).

The article was prepared with financial support from the Russian Foundation for the Humanities (grant No. 15-06-10231a, "Socio-psychological Factors of Successful Smoking Cessation"). 
хологии (Журавлев, 2002; Психология: современные направления ... , 2003). Рассмотрение данного вопроса в психологической науке осуществляется на нескольких уровнях: макросочиальном - изучение влияния СМИ, политики государства, микросоииальном - влияния ближайшего окружения, личностном - влияние индивидуально-психологических особенностей человека (см.: Позняков, Хромова, 2008, 2009, 2010, 2013).

Однако при большом количестве исследований, посвященных данной проблеме, основной акцент делается на причинах табакокурения и дичностных особенностях курильщика. В то же время интерес представляет группа некурящих людей и их отношение к табакокурению.

Психологические отношения представляют собой особые состояния сознания, которые предшествуют поведению человека, а также обнаруживают готовность к данному поведению, что и выражает поведенческий компонент психологических отношений. В структуре психологических отношений выделяют следующие компоненmbl: познавательный, эмоциональный, ценностный и поведенческий (Журавлев, Позняков, 2012; Позняков, 2000, 2012). Познавательный компонент вкдючает в себя знания об объекте отношения, эмоциональный - эмоциональную оценку данного объекта. Ценностный компонент основан на соотнесении субъективной системы ценностей человека и объекта оценивания и связи, в которой данный объект находится с субъектом.

Выделение типа психологического отношения к табакокурению среди некурящих представителей молодежи даст возможность обозначить круг причин некурения, а также составить психологический портрет некурящего человека.

Теоретико-методологические основания исследования: положения системного и субъектного подходов (Б. Г. Ананьев, Б. Ф. Аомов, С. А. Рубинштейн, К. А. Абульханова, В. Г. Асеев, А. В. Брушлинский А. А. Журавлев и Ар.), положения теории психологических отношений (А. Ф. Аазурский, Б. Ф. Аомов, В. Н. Мясищев, В. П. Позняков, И. Р. Сушков и ар.).

Цель исследования: выявить и описать типы психологического отношения некурящих представителей молодежи к табакокурению.

Объект исследования: студенческая молодежь в возрасте от 18 до 22 лет (г. Москва и Московская область).

Предмет исследования: типы психологического отношения некурящих представителей молодежи к табакокурению.

Основная гипотеза: существуют различные типы психологического отношения некурящих представителей молодежи к табакокурению, обусловленные различной выраженностью компонентов отношения.

Аополнительные гипотезы:

1. В качестве основания для выделения типов психологического отношения к табакокурению выступает соотношение компонентов психологического отношения.

2. Существует взаимосвязь между знаниями о последствиях влияния табакокурения на организм человека и его психологическим отношением к табакокурению.

3. Существует взаимосвязь между эмоционально нейтральным или эмоционально негативным оцениванием табакокурения и психологическим отношением к табакокурению.

4. Существует взаимосвязь между психологическим отношением к табакокурению и ценностными ориентациями личности.

Задачи исследования. Теоретические задачи: 
1. Провести теоретический анализ социально-психологических исследований табакокурения.

2. Провести теоретико-методологический анализ понятия «отношение».

3. Разработать авторский концептуальный подход к исследованию типов психологического отношения к табакокурению среди некурящих представителей молодежи.

Методическая задача - разработать авторскую анкету для изучения психологического отношения к табакокурению среди некурящих представителей молодежи.

Эмпирические задачи:

1. Провести пилотажное исследование для выделения оптимальной совокупности методик, а также для корректировки вопросов авторской анкеты.

2. Эмпирически выявить и исследовать типы психологического отношения к табакокурению среди некурящих представителей молодежи.

3. Составить социально-психологический портрет некурящего представителя молодежи.

4. Изучить индивидуально-психологические особенности некурящих представителей молодежи с разным типом отношения к табакокурению.

5. Провести анализ влияния ценностных ориентаций на психологическое отношение к табакокурению.

Методический инструментарий:

1. Теоретический анализ.

2. Авторская анкета «Исследование психологического отношения к табакокурению».

3. Методика «Уровень соотношения “ценности” и “доступности” в раздичных жизненных сферах» (Е. Б. Фанталова) (для диагностики ценностного компонента отношений).

4. Цветовой тест отношений применительно к табакокурению (для диагностики эмоционального отношения к данному феномену).

5. Семантический дифференциал (для диагностики неосознаваемых компонентов психологических отношений).

6. 16-факторный личностный опросник Кеттелла, позволяющий рассмотреть личностные характеристики некурящего человека.

\section{ПРОГРАММА ИССАЕАОВАНИЯ ТИПОВ ПСИХОАОГИЧЕСКОГО ОТНОШЕНИЯ К ТАБАКОКУРЕНИЮ}

Эman 1. Предварительный этап, в рамках которого прорабатывался методический аппарат исследования, проводился теоретический анализ социально-психологических исследований табакокурения и понятия «отношение».

Эman 2. Включал в себя пилотажное исследование, цели которого: выделение оптимальной совокупности методик, корректировка вопросов авторской анкеты «Исследование психологического отношения к табакокурению», уточнение задач основного этапа исследования.

Эman 3. Основной этап исследования нацелен на решение эмпирических задач 2-5, а именно эмпирически выявить и проанализировать типы психологического отношения к табакокурению среди некурящих представителей молодежи, составить социально-психологический портрет некурящего представителя молодежи, провести анализ индивидуально-психологических особенностей некурящих представителей молодежи. Важной частью третьего этапа является также анализ влияния ценностных ориентаций дичности на психологическое отношение к табакокурению. 


\section{АНАИИЗ РЕЗУАЬТАТОВ ПИАОТАЖНОГО ИССАЕАОВАНИЯ}

В пилотажном исследовании, проведенном в декабре 2014 г., приняли участие 40 студентов очного отделения факультета педагогики и психологии Московского педагогического государственного университета (МПГУ). Аля сбора эмпирических данных были использованы все заявленные методики. Статистическая обработка результатов проводилась в программах MS Excel и SPSS 11.0. Аля выделения типов психологического отношения к табакокурению в рамках пилотажного исследования использовался кластерный анализ. Аанный метод дает возможность упорядочивать объекты в относительно однородные группы на основании попарного сравнения этих объектов по заранее заданным и измеренным критериям. В настоящем исследовании использован иерархический кластерный анализ для выделения оптимального числа классов и кластерный анализ K-means для группировки респондентов в типы.

Таким образом, массив данных, полученный при применении методик «Уровень соотношения “ценности” и “доступности” в различных жизненных сферах» (Е. Б. Фанталова), цветовой тест отношений применительно к табакокурению, семантический дифференциал и авторская анкета «Исследование психологического отношения к табакокурению», был подвергнут кластерному анализу для определения групп респондентов с достоверно схожими результатами.

В итоге проведенного кластерного анализа были выделены четыре группы респондентов. В первой группе оказалось 16 , во второй -7 , в третьей -9 и в четвертой 8 человек. Статистически значимых различий в когнитивном и поведенческом компонентах психологического отношения к курению между представителями данных групп получено не было, однако данные группы различны по эмоциональному (методика семантического дифференциала) и ценностному (методика «Уровень соотношения “ценности” и “доступности” в различных жизненных сферах») компонентам.

Первая группа применительно к табакокурению использует такие прилагательные, как «темный», «противный», «унылый» и «ненавистный». Аля курящего человека - «печальный», «слабый», «гнилой». Относительно некурящего человека выбирают такие прилагательные, как «светлый», «жизнерадостный» и «свежий». У респондентов данной группы наблюдается внутренний «вакуум» (ощущение ненужности, когда объект доступен, но не является ценным для человека) относительно таких ценностей, как интересная работа и любовь.

Вторая группа для описания своего отношения к табакокурению использует такие прилагательные, как «тяжелый», «противный», «твердый», «ненавистный», «гнилой» и «глупый». Относительно курящего человека - «слабый», «ненавистный», «глупый» и «грязный». Аля некурящего человека используют такие прилагательные, как «сильный», «хороший», «приятный», «упорядоченный», «свежий»и «чистый». У респондентов данной группы - внутренний «вакуум» для таких ценностей, как активная жизнь и красота природы. Также у данной группы выявлен внутренний конфликт когда значимые ценности малодоступны - относительно таких ценностей, как свобода, независимость и счастливая семейная жизнь.

Третья группа респондентов при оценивании понятия «табакокурение» и курящего человека использует нейтральные прилагательные, без негативной или позитивной окраски. При оценивании некурящего человека чаще используются прилагательные «упорядоченный», «легкий» и «умный». У данной группы респондентов наблюдается внутренний конфликт относительно таких ценностей, как «любовь», «наличие хороших и верных друзей» и «счастливая семейная жизнь». Внутренний «вакуум» обнару- 
жен относительно ценностей «активная жизнь», «уверенность в себе» и «свобода как независимость».

Четвертая группа респондентов применительно к табакокурению использует такие прилагательные, как «тяжелый», «темный», «противный», «напряженный», «чужой», «злой». Аля описания курящего человека - «тяжелый», «печальный», «злой», «унылый», «гнилой». Некурящего человека оценивают как «легкого», «радостного», «большого», «светлого». Аанная группа респондентов при оценивании степени выраженности характеристики применительно к понятиям табакокурение, курящий и некурящий человек использует крайнюю степень выраженности. У данной группы внутренний «вакуум» имеет место относительно таких ценностей, как «активная жизнь», «интересная работа», «красота природы», «уверенность в себе» и «свобода как независимость». Внутренний конфликт проявляется относительно ценностей «здоровье», «любовь» и «счастливая семейная жизнь».

Аля статистического обоснования правомерности выделенной типологии был применен дискриминантный анализ, который показывает вклад переменных в общую дискриминацию между типами психологических отношений, а также обнаруживает переменные, которые вносят наибольший вклад в общую дискриминацию. Статистически значимое влияние (16-факторный личностный опросник Кеттелла) оказывают факторы E (подчиненность - властность), G (безответственность - ответственность), М (практичный - творческий).

\section{ЗАКАЮЧЕНИЕ}

Полученные в пилотажном исследовании результаты дали основания для корректировки задач исследования, для выбора наиболее оптимальной совокупности методик и для внесения изменений в вопросы авторской анкеты «Исследование психологического отношения к табакокурению».

На основном этапе исследования (в апреле - октябре 2015 г.) планируется сбор основного эмпирического материала, выборка - 100 чел., эмпирически выделить типы психологического отношения к табакокурению среди некурящих представителей молодежи, проанализировать соотношение компонентов психологического отношения к табакокурению. Особое внимание будет уделяться анализу взаимосвязи ценностных ориентаций и психологического отношения к табакокурению.

\section{СПИСОК АИТЕРАТУРЫ}

Журавлев, А. А. (2002) Специфика междисциплинарных исследований в психологии // Психологический журнал. Т. 23. № 6. С. 83-88.

Журавлев, А. А., Позняков, В. П. (2012) Социальная психология российского предпринимательства: концепция психологических отношений. М. : ИзА-во Института психологии РАН. $480 \mathrm{c.}$

Позняков, В. П. (2000) Психологические отношения субъектов экономической деятельности. М. : ИзА-во Института психологии РАН. 220 с.

Позняков, В. П. (2012) Психологические отношения индивидуальных и групповых субъектов совместной жизнедеятельности // Психологический журнал. Т. 33. № 5. С. 5-15.

Позняков, В. П., Хромова, В. А. (2008) Социально-психологические особенности отношения к табакокурению у курящих и некурящих мужчин и женщин (начало) // Знание. Понимание. Умение. № 4. С. 193-198.

Позняков, В. П., Хромова, В. А. (2009) Социально-психологические особенности отношения к табакокурению у курящих и некурящих мужчин и женщин (окончание) // Знание. Понимание. Умение. № 1. С. 196-200. 
Позняков, В. П., Хромова, В. А. (2010) Социально-психологическое исследование отношения к табакокурению. М. : Изд-во Моск. гуманит. ун-та. 178 с.

Позняков, В. П., Хромова, В. $\Lambda$. (2013) Различия в отношении к табакокурению у групп курящих и некурящих мужчин и женщин // Психологические исследования проблем современного российского общества / под ред. А. А. Журавлева, Е. А. Сергиенко. М. : Изд-во Института психологии РАН. 502 с. С. 132-156.

Психология: современные направления междисциплинарных исследований (2003) : материалы научной конференции / отв. ред. А. А. Журавлев, Н. В. Тарабрина. М. : ИзА-во Института психологии РАН. 488 с.

Аата поступления: 10.02.2015 2.

\section{A RESEARCH PROGRAM FOR STUDYING TYPES OF PSYCHOLOGICAL ATTITUDES \\ TO SMOKING (THE CASE OF YOUNG NON-SMOKERS) \\ V. P. POZNYAKOV}

(THE INSTITUTE OF PSYCHOLOGY OF THE RUSSIAN ACADEMY OF SCIENCES; MOSCOW UNIVERSITY FOR THE HUMANITIES)

\section{S. A. RESHETKO}

\section{(THE INSTITUTE OF PSYCHOLOGY OF THE RUSSIAN ACADEMY OF SCIENCES)}

The article presents a research program for studying types of psychological attitudes to smoking among young non-smokers. According to the contemporary debates in Russian psychology on the issue of psychological relations (A.L. Zhuravlev, V.P. Poznyakov), their structure includes such components as cognitive, emotional, behavioral and evaluative. In this study, we suppose that different types of psychological attitudes to smoking are determined by different content combinations of these components.

The aim of this study is to identify and describe the types of psychological attitudes to smoking among non-smoking young people. The objects of the study were non-smoking students aged 18 to 22 years (residents of Moscow and the Moscow oblast). To collect empirical data we used such techniques as our self-developed questionnaire "Researching psychological attitude to smoking", "The level of correlation between value and accessibility" technique (E. B. Fantalova), color test of attitudes to smoking, semantic differential and the Cattell sixteen personality factor test.

This article sums up the outcomes of the first two phases of the study. The first one consisted of a theoretical and methodological analysis of psychological studies of smoking and the concept of "attitude". The second stage included a pilot study aimed a readjusting the research objectives, as well as the survey questions. This data was processed by means of cluster analysis to produce four groups of subjects, differing by their components of psychological attitudes to smoking.

The discriminant analysis allowed us to outline significant socio-psychological characteristics of non-smoking youth. Among all indicators, the greatest significance have been assigned to $\mathrm{E}$ (subordination - authoritativeness), G (irresponsibility - responsibility), and $\mathrm{M}$ (pragmatic - creative) (according to the Cattell test).

The next stage of our research will include the main empirical study.

Keywords: tobacco smoking, psychological attitudes, youth, non-smokers, attitude towards smoking.

\section{REFERENCES}

Zhuravlev, A. L. (2002) Spetsifika mezhdistsiplinarnykh issledovanii v psikhologii [The specificity of interdisciplinary research in psychology]. Psikhologicheskii zhurnal, vol. 23, no. 6, pp. 83-88. (In Russ.).

Zhuravlev, A. L. and Poznyakov, V. P. (2012) Sotsial'naia psikhologiia rossiiskogo predprinimatel'stva: kontseptsiia psikhologicheskikh otnoshenii [The social psychology of Russian entrepreneurship: The concept of psychological relations]. Moscow, Publishing House of the Institute of Psychology, RAS. 480 p. (In Russ.). 
Poznyakov, V. P. (2000) Psikhologicheskie otnosheniia sub'ektov ekonomicheskoi deiatel'nosti [Psychological relations between the subjects of economic activity]. Moscow, Publishing House of the Institute of Psychology, RAS. 220 p. (In Russ.).

Poznyakov, V. P. (2012) Psikhologicheskie otnosheniia individual'nykh i gruppovykh subektov sovmestnoi zhiznedeiatel'nosti [Psychological relations between individual and collective subjects of joint activities]. Psikhologicheskii zhurnal, vol. 33, no. 5, pp. 5-15. (In Russ.).

Poznyakov, V. P. and Khromova, V. L. (2008) Sotsial'no-psikhologicheskie osobennosti otnosheniia $\mathrm{k}$ tabakokureniiu u kuriashchikh i nekuriashchikh muzhchin i zhenshchin [Social and psychological features of attitudes toward tobacco smoking among smoking and nonsmoking men and women (the beginning)]. Znanie. Ponimanie. Umenie, no. 4, pp. 193-198. (In Russ.).

Poznyakov, V. P. and Khromova, V. L. (2009) Sotsial'no-psikhologicheskie osobennosti otnosheniia $\mathrm{k}$ tabakokureniiu u kuriashchikh i nekuriashchikh muzhchin i zhenshchin [Social and psychological features of attitudes toward tobacco smoking among smoking and nonsmoking men and women (the ending)]. Znanie. Ponimanie. Umenie, no. 1, pp. 196-200. (In Russ.).

Poznyakov, V. P. and Khromova, V. L. (2010) Sotsial'no-psikhologicheskoe issledovanie otnosheniia $\mathrm{k}$ tabakokureniiu [A socio-psychological research of attitudes to tobacco smoking]. Moscow, Moscow University for the Humanities Publ. 178 p. (In Russ.).

Poznyakov, V. P. and Khromova, V. L. (2013) Razlichiia v otnoshenii k tabakokureniiu u grupp kuriashchikh i nekuriashchikh muzhchin i zhenshchin [Differences in attitudes to smoking among groups of male and female smokers and non-smokers]. In: Psikhologicheskie issledovaniia problem sovremennogo rossiiskogo obshchestva [Psychological research into problems of contemporary Russian society] / ed. by A. L. Zhuravlev and E. A. Sergienko. Moscow, Publishing House of the Institute of Psychology, RAS. 502 p. Pp. 132-156. (In Russ.).

Psikhologiia: sovremennye napravleniia mezhdistsiplinarnykh issledovanii [Psychology: modern research guidelines in psychology] (2003) : Conference proceedings / ed. by A. L. Zhuravlev and N. V. Tarabrina. Moscow, Publishing House of the Institute of Psychology, RAS. 488 p. (In Russ.).

Submission date: 10.02 .2015$.

Позняков Владимир Петрович - доктор психологических наук, главный научный сотрудник лаборатории социальной и экономической психологии Института психологии РАН, профессор кафедры социальной и этнической психологии Московского гуманитарного университета, член-корреспондент Международной академии психологических наук. Адрес: 129366, Россия, г. Москва, ул. Ярославская, д. 13. Тел./факс: +7 (495) 682-72-70; +7 (499) 374-56-11. Эл. адpec: pozn_v@mail.ru

Решетко Светлана Альбертовна - аспирант лаборатории социальной и экономической психологии Института психологии РАН. Адрес: 129366, Россия, г. Москва, ул. Ярославская, А. 13. Тел.: +7 (495) 682-72-70. Эл. адрес: swetlana.reshetko@yandex.ru. Научный руководитель — A-p психол. наук, проф. В. П. Позняков.

Poznyakov Vladimir Petrovich, Doctor of Psychology, Leading Research Fellow, Laboratory of Social and Economic Psychology, Institute of Psychology, Russian Academy of Sciences; Professor, Department of Social and Ethnic Psychology, Moscow University for the Humanities; Corresponding member, International Academy of Psychological Science (IAPS). Postal address: 13 Yaroslavskaya St., 129366 Moscow, Russian Federation. Tel./fax: +7 (495) 682-72-70; +7 (499) 374-56-11. E-mail: pozn_v@mail.ru

Reshetko Svetlana Albertovna, Postgraduate Student, Laboratory of Social and Economic Psychology, Institute of Psychology, Russian Academy of Sciences. Postal address: 13 Yaroslavskaya St., 129366 Moscow, Russian Federation. Tel./fax: +7 (495) 682-72-70. E-mail: swetlana.reshetko@yandex.ru. Research adviser: V. P. Poznyakov, Doctor of Psychology, Professor. 